\title{
Heat shock response and homeostatic plasticity
}

\author{
Shanker Karunanithi ${ }^{1,2 *}$ and lan R. Brown ${ }^{3}$ \\ ${ }^{1}$ School of Medical Science, Griffith University, QLD, Australia, ${ }^{2}$ Menzies Health Institute of Queensland, Griffith University, \\ QLD, Australia, ${ }^{3}$ Department of Biological Sciences, Centre for the Neurobiology of Stress, University of Toronto \\ Scarborough, Toronto, ON, Canada
}

Heat shock response and homeostatic plasticity are mechanisms that afford functional stability to cells in the face of stress. Each mechanism has been investigated independently, but the link between the two has not been extensively explored. We explore this link. The heat shock response enables cells to adapt to stresses such as high temperature, metabolic stress and reduced oxygen levels. This mechanism results from the production of heat shock proteins (HSPs) which maintain normal cellular functions by counteracting the misfolding of cellular proteins. Homeostatic plasticity enables neurons and their target cells to maintain their activity levels around their respective set points in the face of stress or disturbances. This mechanism results from the recruitment of adaptations at synaptic inputs, or at voltage-gated ion channels. In this perspective, we argue that heat shock triggers homeostatic plasticity through the production of HSPs. We also suggest that homeostatic plasticity is a form of neuroprotection.

OPEN ACCESS

Edited by: Arianna Maffei, SUNY Stony Brook, USA

Reviewed by: Dion Dickman, University of Southern California, USA Kara Geo Pratt, University of Wyoming, USA

${ }^{*}$ Correspondence: Shanker Karunanithi, School of Medical Science, Griffith University, Gold Coast Campus,

QLD 4222, Australia s.karunanithi@griffith.edu.au

Received: 09 January 2015 Accepted: 17 February 2015 Published: 12 March 2015

Citation: Karunanithi S and Brown IR (2015) Heat shock response and homeostatic plasticity. Front. Cell. Neurosci. 9:68. doi: 10.3389/fncel.2015.00068
Keywords: adaptations, temperature, neuronal activity, Drosophila neuromuscular junction, synaptic homeostasis, action potentials and neuroprotection

\section{Introduction}

The nervous system is particularly vulnerable to heat damage (Kourtis et al., 2012). However, it is well established that if organisms have been exposed to sublethal temperatures for brief periods (heat shock) and subsequently encounter lethal temperatures, their nervous systems will be protected from damage (Brown, 2007; Buccellato et al., 2007; Stetler et al., 2010; Robertson and Money, 2012). The protection afforded by heat shock is referred to as the heat shock response. Stressors other than elevated temperature, such as hypoxia, metabolic shock and hypothermia can also induce the heat shock response (Parsell and Lindquist, 1993; Gidalevitz et al., 2011; Morimoto, 2011). Therefore the response can be regarded as generally protective. The response occurs as a result of recruiting cellular adaptations during heat shock (Parsell and Lindquist, 1993; Latchman, 2004; Brown, 2007; Gidalevitz et al., 2011; Morimoto, 2011; van Oosten-Hawle and Morimoto, 2014). The response is found to be physiologically beneficial because it is induced within the mammalian nervous system following a fever-like increase in body temperature or through tissue injury (Brown, 2007; Asea and Brown, 2008).

Despite the existence of a large body of knowledge regarding the heat shock response, there is poor understanding of its protective effects on neuronal function. By reviewing the literature, we argue that the response contributes towards preserving a key functional parameter of neurons- neuronal activity- within their narrow physiological ranges at elevated temperatures. 


\section{Homeostatic Plasticity}

In early life, neurons acquire their structural and functional characteristics which remain with them throughout the rest of their lifetime (Marder and Goaillard, 2006). An important problem that is at the forefront of research is to understand how neurons preserve their signature characteristics throughout their lifetime despite being subjected to stress, modification and rebuilding (Marder and Prinz, 2002; Marder and Goaillard, 2006). A key characteristic that is thought to be tightly regulated throughout a neuron's lifetime is neuronal activity or the action potential firing rate, which carries information for producing behaviors (Marder and Goaillard, 2006; Debanne et al., 2011; Bishop and Zito, 2013; Hengen et al., 2013; Keck et al., 2013). The preservation of neuronal activity around a set point (target level) is thought to be key to the maintenance of nervous system function in the face of stress, insults or disturbances (Marder and Prinz, 2002; Turrigiano and Nelson, 2004; Turrigiano, 2008; Davis, 2013; Figure 1). The mechanism that preserves neuronal activity around a set point is referred to as homeostatic plasticity (Turrigiano and Nelson, 2004; Davis, 2013).

Research over the past 20 years indicates that homeostatic plasticity can result from adaptations which alter the strengths of synapses or the properties of ion channels (other than postsynaptic ligand-gated channels) that control neuronal excitability, or both (Turrigiano, 1999, 2012; Marder and Prinz, 2002; Turrigiano and Nelson, 2004). The adaptations at synapses are referred to as homeostatic synaptic plasticity, whereas those at ion channels are referred to as homeostatic intrinsic plasticity (Desai, 2003; Misonou, 2010).

\section{Neuroprotection and Homeostatic Plasticity}

Neuroprotection refers to the preservation of neuronal structure or function, or both, against insults (Casson et al., 2012). Up to now, the heat shock response has been considered as a mechanism that affords neuroprotection (Brown, 2007).

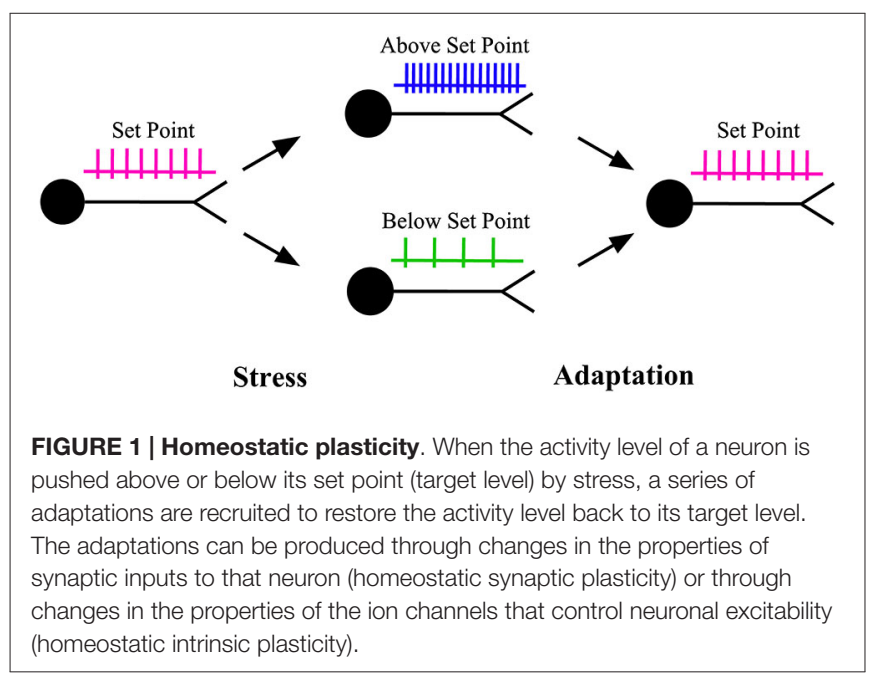

Whether the response can also be considered as a mechanism that affords homeostatic plasticity has not been explored (Davis, 2006; Brown, 2007; Robertson and Money, 2012). Interestingly, homeostatic plasticity appears to fall within the definition of neuroprotection because it describes the preservation of neuronal function against insults. By reviewing publications investigating the role of heat shock on neuronal function, we argue that the effects of heat shock, which are considered to be neuroprotection could also be homeostatic plasticity. Specifically, we will examine the heat shock response at elevated temperatures.

\section{Heat Shock Proteins}

When organisms receive a heat shock, the synthesis of most cellular proteins is downregulated with the exception of a small class of proteins, which includes HSPs (Parsell and Lindquist, 1993; Morimoto, 2011). HSPs maintain cellular integrity by preventing other cellular proteins from unfolding or degrading, or preventing unfolded proteins from aggregating (Gidalevitz et al., 2011). HSPs are classified according to their molecular mass (for example, HSP40 represents the HSP that is $40 \mathrm{kDa}$ in mass) and grouped into the following families: HSP100, HSP90, HSP70, HSP40, small HSPs and chaperonins (Kampinga et al., 2009; De Maio and Vazquez, 2013).

HSPs that are present in unstressed cells are referred to as constitutive HSPs or molecular chaperones whereas those that are expressed following stress are referred to as stress proteins or induced HSPs (De Maio, 1999; De Maio and Vazquez, 2013; Saibil, 2013). Constitutive HSPs, such as HSP90, HSP40 and HSC70 perform housekeeping functions within cells (De Maio, 1999; Hartl and Hayer-Hartl, 2009; Saibil, 2013). Induced HSPs, such as HSP70 (which is the most abundantly induced HSP following heat shock), are involved in folding proteins correctly and preventing the aggregation of unfolded proteins (De Maio, 1999; Saibil, 2013). In brain cells, hyperthermia triggers a robust expression of induced HSPs, such as HSP70, HSP32 and HSP27 (Brown, 2007; Asea and Brown, 2008).

\section{Heat Shock and Homeostatic Synaptic Plasticity}

Synapses are the critical sites of cell-to-cell communication within the nervous system. To prevent communication breakdown under stressful conditions, synapses need to remain functional (Karunanithi et al., 1999, 2002). Heat shock is shown to be beneficial in preserving synapse function at elevated temperatures (Freedman et al., 1981; Dawson-Scully and Meldrum Robertson, 1998; Karunanithi et al., 1999, 2002; Kelty et al., 2002; Klose et al., 2004, 2008; Newman et al., 2005). However, the underlying mechanisms have not been extensively explored. In this section, we will review the effects of heat shock on synapse function and suggest that the observed changes could be homeostatic synaptic plasticity. 
An important parameter that represents the effectiveness of synaptic transmission is synaptic strength. Synaptic strength is defined as the average size of the postsynaptic responses produced upon nerve stimulation at low frequencies, or the response on initial stimulation during a train of stimuli (Atwood and Karunanithi, 2002). In homeostatic synaptic plasticity, synaptic strengths are adjusted in a manner that lead to the preservation of neuronal activity around a set point (Turrigiano, 1999, 2011; Burrone and Murthy, 2003). In some cases of homeostatic synaptic plasticity, synaptic strengths are maintained at a constant value. This form of plasticity is referred to as synaptic homeostasis (Stewart et al., 1996; Turrigiano, 1999; Davis, 2013; Wang et al., 2014; Davis and Müller, 2015).

Current findings indicate that synaptic homeostasis leads to the preservation of muscle activity around a set point (Davis, 2006, 2013). At the Drosophila larval neuromuscular junction (NMJ), synaptic strengths were attenuated above room temperature $\left(22^{\circ} \mathrm{C}\right)$ (Karunanithi et al., 1999). However, Drosophila larvae that received a prior heat shock displayed synaptic homeostasis, where synaptic strengths were maintained up to temperatures $9^{\circ} \mathrm{C}$ higher than room temperature (Karunanithi et al., 1999; Figure 2A). Heat shock also afforded synaptic homeostasis at the locust NMJ (Dawson-Scully and Meldrum Robertson, 1998; Barclay and Robertson, 2000). These findings indicate that heat shock affords synaptic homeostasis at elevated temperatures, preventing decreases in the levels of synaptic excitation of the muscle.

What are the factor(s) which heat shock protects to afford synaptic homeostasis? At the Drosophila larval NMJ, the most significant factor which heat shock protected at elevated temperatures was nerve-evoked neurotransmitter release (Karunanithi et al., 1999, 2002; Figure 2A). An absolute requirement for nerve-evoked neurotransmitter release is calcium entry into nerve terminals through voltage-gated calcium channels (VGCCs; Macleod et al., 2006). Results indicate that the preservation of neurotransmitter release at elevated temperatures following heat shock may partly result from the preservation of calcium entry through VGCCs (Klose et al., 2008).

Overwhelming evidence indicates that homeostatic synaptic plasticity is calcium dependent (Pozo and Goda, 2010; Turrigiano, 2012). At heat shocked Drosophila larval NMJs, intracellular calcium-handling mechanisms that contribute toward sustaining neurotransmitter release at elevated temperatures were protected (Klose et al., 2008, 2009). Resting calcium concentration and calcium clearance were maintained above the upper temperature limit of the organism (Klose et al., 2008). Protection of such calcium-handling mechanisms following heat shock may lead to greater availability of calcium to the release machinery to sustain neurotransmitter release at elevated temperatures (Barclay and Robertson, 2003; Klose et al., 2008). The available data suggests that these mechanisms may contribute towards affording synaptic homeostasis at elevated temperatures.

Following heat shock, which molecules are responsible for establishing synaptic homeostasis? The extensive work of Brown et al. has shown that following heat shock, HSPs localize at
A
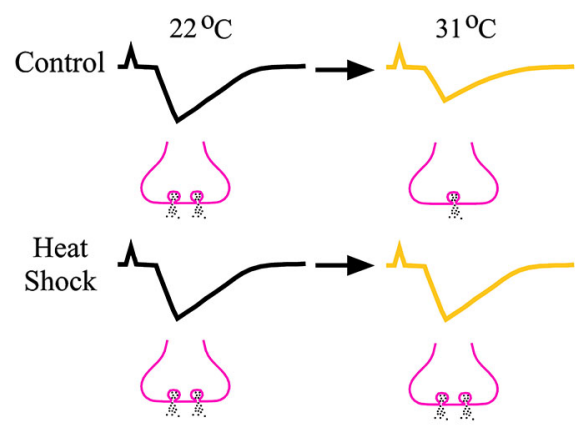

B

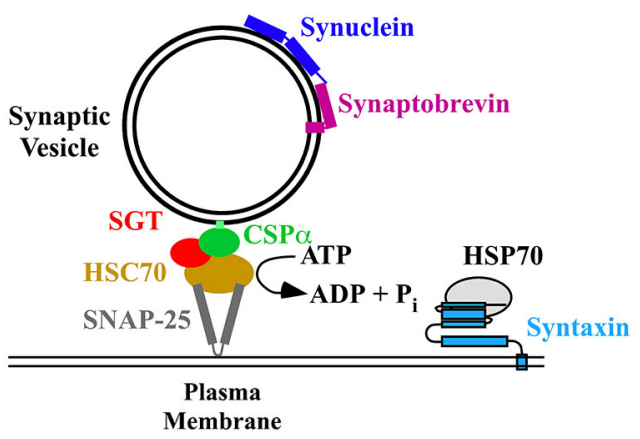

FIGURE 2 | (A) Synaptic homeostasis following heat shock. In control Drosophila larvae that did not receive a prior heat shock, synaptic strength (upper traces) decreased at $31^{\circ} \mathrm{C}$ compared to room temperature $\left(22^{\circ} \mathrm{C}\right)$ through a decrease in neurotransmitter release (fewer vesicles releasing neurotransmitter). Following heat shock, synaptic strength (lower traces) at $31^{\circ} \mathrm{C}$ was maintained at the same value as that observed at $22^{\circ} \mathrm{C}$ by preventing a decrease in neurotransmitter release (the same number of vesicles releasing neurotransmitter). (B) Induced HSPs and chaperones neuroprotect the neurotransmitter release machinery. The diagram shows the chaperones and some of the proteins which constitute the release machinery (Rizo and Südhof, 2012). Chaperones prevent proteins from unfolding, or engaging in unwanted interactions, or both. They maintain proteins that constitute the neurotransmitter release machinery in a release-ready state before calcium-triggered synaptic vesicle exocytosis. The CSP/HSC70/SGT (small glutamine-rich protein) complex chaperones SNAP-25, and synuclein chaperones synaptobrevin, maintaining SNAP-25 and synaptobrevin, respectively, in a release-ready state. Upon release from the chaperones, synaptobrevin rapidly assembles with SNAP-25 and syntaxin, forming the SNARE complex that leads to exocytosis. The CSP complex operates in an ATP-dependent manner, whereas synuclein operates in an ATP-independent manner. HSP70 is reported to interact with syntaxin (Fei et al., 2007). HSP70 could protect syntaxin from becoming compromised under stress, enabling syntaxin to form the SNARE complex and undergo exocytosis.

mammalian synapses (Freedman et al., 1981; Bechtold and Brown, 2000, 2003; Bechtold et al., 2000; Chen and Brown, 2007; Asea and Brown, 2008). Existing literature strongly argues that HSPs afford protection to synapses, especially HSP70. Studies have shown that HSP70 is rapidly induced by heat shock (Tissières et al., 1974; Parsell and Lindquist, 1993; Feder et al., 1996). In heat shocked Drosophila larvae, synaptic strength at the larval NMJ paralleled the levels of HSP70 expressed in the organism (Karunanithi et al., 1999, 2002). Targeting HSP70 to Drosophila motor neurons 
induced structural plasticity of axonal terminals resulting in increased neurotransmitter release at elevated temperatures at the larval NMJ (Xiao et al., 2007). Presynaptic calcium entry, resting calcium concentrations and calcium clearance were uncompromised at elevated temperatures when HSP70 was overexpressed into motor neurons (Klose et al., 2008). HSP70 is also thought to protect calcium-handling proteins, such as sarcoendoplasmic reticulum calcium-ATPase (SERCA; Klose et al., 2008). SERCA regulates endoplasmic reticulum calcium stores to control intracellular calcium concentrations (Klose et al., 2008). These results suggest, that following heat shock, induced HSP70 sustains neurotransmitter release at elevated temperatures to afford synaptic homeostasis (Fei et al., 2007, 2008; Xiao et al., 2007).

In Drosophila mutant larvae that fail to produce induced HSPs following heat shock, there was a compensatory upregulation of constitutive HSPs (Neal et al., 2006). This upregulation contributed to the preservation of synaptic function at elevated temperatures (Neal et al., 2006). Presynaptic proteins other than HSPs, such as cysteine string protein (CSP) and $\alpha$-synuclein, have also been reported to protect the transmitter release machinery from failing (Burré et al., 2010; Sharma et al., 2011). CSP is found to afford protection by interacting with constitutive HSPs, such as HSC70 (Bronk et al., 2001, 2005; Sharma et al., 2011; Figure 2B). These results suggest that proteins other than induced HSPs could also prevent failure of neurotransmitter release.

\section{Heat Shock and Homeostatic Intrinsic Plasticity}

When organisms are in danger or under stress, their nervous systems need to be able to produce action potentials in order to help them generate escape behaviors (such as behaviors that enable organisms to escape from prey or from the heat on hot days) (Barclay and Robertson, 2000; Money et al., 2005; Feder et al., 2010). The collective evidence indicates that heat shock alters the properties of voltage-gated ion channels in order to sustain action potential firing at elevated temperatures.

In motor neurons that control locust flight muscles, heat shock increased the upper temperature limit at which action potentials could fire, preventing action potential failure at elevated temperatures ( $\mathrm{Wu}$ et al., 2001). Decreases in $\mathrm{K}^{+}$currents increased action potential duration to prevent action potential failure at elevated temperatures ( $\mathrm{Wu}$ et al., 2001). In locust motor neurons and visual interneurons, heat shock produced an increase in action potential amplitude at elevated temperatures (Wu et al., 2001; Money et al., 2005). That effect could be due to heat shock preventing the inactivation of voltage-gated $\mathrm{Na}^{+}$channels at elevated temperatures (Money et al., 2005). These results indicate that heat shock promotes a form of homeostatic intrinsic plasticity where the conductance of voltage-gated $\mathrm{Na}^{+}$and $\mathrm{K}^{+}$ channels are altered to enable action potential firing at elevated temperatures.
HSP interactions with voltage-gated ion channels that aid action potential firing are poorly understood. In previous work, HSPs were found to interact with VGCCs (Krieger et al., 2006) and voltage-gated potassium channels (Ramirez et al., 1999; Clay and Kuzirian, 2002; Ficker et al., 2003; Wray, 2009; Gao et al., 2013a,b). In HEK cells, HSP70 was proposed to aid the targeting of protein kinase $\mathrm{C}$ to specific regions of the voltage-gated $\mathrm{Ca}_{v} 2.3$ calcium channel (Krieger et al., 2006). $\mathrm{K}_{v} 7.4$ voltage-gated potassium channels are found on the outer hair cell membranes of the inner ear and are involved in the conduction of sound (Gao et al., 2013a,b). Overexpression of HSP90 was found to prevent the loss of surface $\mathrm{K}_{v} 7.4$ channels on HEK cells (Gao et al., 2013a,b), suggesting that overexpression of HSP90 could prevent hearing loss. These findings indicate that HSPs could potentially interact with voltage-gated ion channels to induce homeostatic intrinsic plasticity.

Studies have shown that there are additional benefits afforded by heat shock in the reliable generation of action potentials at elevated temperatures (Money et al., 2005, 2009; Hou et al., 2014). First, there was increased hyperpolarization of the membrane to maintain action potential amplitude. At elevated temperatures, there is a build up of extracellular $\mathrm{K}^{+}$ that depolarizes the membrane, preventing the generation of action potentials. Heat shock prevented this build up by causing the clearance of extracellular $\mathrm{K}^{+}$through insertion of more $\mathrm{Na}^{+} / \mathrm{K}^{+}$-ATPase pumps into the cell membrane. These pumps are designed to move $\mathrm{K}^{+}$into the cell and this movement probably contributed to the hyperpolarization (Money et al., 2009; Hou et al., 2014). The idea that active transporters can alter membrane excitability is further supported by recent work showing that in Drosophila larval motor neurons, changes in $\mathrm{Na}^{+} / \mathrm{K}^{+}$-ATPase pump function can lead to long-lasting changes in membrane excitability (Pulver and Griffith, 2010). Second, there was increased membrane excitability to enable generation of high frequency bursts of action potentials (Money et al., 2005). For example, heat shock has been shown to increase membrane excitability by increasing the afterdepolarizations following an action potential. The afterdepolarizations lower the threshold for subsequent action potential firing. Prolonging the conductance of $\mathrm{Na}^{+}$, or $\mathrm{Ca}^{2+}$ or another non-selective cation channel is thought to produce these afterdepolarizations. Alternatively, a reduction in $\mathrm{K}^{+}$conductance could be another means for generating afterdepolarizations (Money et al., 2005). These results indicate that heat shock may recruit homeostatic intrinsic plasticity through alterations in not just the properties of voltage-gated ion channels, but also those of active-transporters.

Early work from the Tytell laboratory conducted on the squid giant axon showed that heat shock caused HSP70 to be rapidly synthesized and transferred from the surrounding glia into the axon (Tytell et al., 1986). This glia to neuron transfer may provide a mechanism for fast delivery of HSPs that may play a functional role in axons (Armstrong et al., 2011). Previous work has shown that HSP70 promotes the anchoring of $\mathrm{Na}^{+} / \mathrm{K}^{+}$. ATPase pumps to the cytoskeletal network located just beneath the neuronal membrane (Riordan et al., 2005; Ruete et al., 2008). By preventing the loss of such pumps from the membrane, the 
build up of extracellular $\mathrm{K}^{+}$at elevated temperatures could be reduced to promote membrane hyperpolarization and action potential firing. In another example, hyperthermia caused the production of HSP27 and HSP32 in perisynaptic glial cells which surround synapses. These HSPs were then transferred into the synapses to potentially afford them protection (Bechtold and Brown, 2003). These results suggest that the transfer of HSPs into neurons from glia provides neuroprotection and could be a means of preventing action potential failure under stress.

\section{Heat Shock and Homeostatic Plasticity}

It is thought that if homeostatic plasticity preserves the normal activity of individual neural circuit elements, the circuit itself should be afforded functional stability (Turrigiano, 2011, 2012). Observations in the locomotory systems of Drosophila and locusts suggest that heat shock affords functional stability to neural circuits under stress by recruiting homeostatic plasticity. Motor patterns are rhythmic bursts of electrical activity that are generated by motor circuits to drive movements (Barclay et al., 2002). Previous work has shown that motor patterns were compromised at elevated temperatures in Drosophila and locusts (Robertson et al., 1996; Klose et al., 2005; Robertson and Money, 2012). However, this is prevented if they receive a prior heat shock (Robertson et al., 1996; Klose et al., 2005). In Drosophila, previous work has shown that, by overexpressing HSP70 in motor neurons, synaptic performance is improved at elevated temperatures, protecting larval locomotion (Xiao et al., 2007). Therefore it appears that a prior heat shock can protect neural circuit function at elevated temperatures. It remains to be determined whether this occurs by homeostatically maintaining the normal activity of individual neural circuit elements.

\section{References}

Armstrong, G. A., Xiao, C., Krill, J. L., Seroude, L., Dawson-Scully, K., and Robertson, R. M. (2011). Glial Hsp70 protects $\mathrm{K}^{+}$homeostasis in the Drosophila brain during repetitive anoxic depolarization. PLoS One 6:e28994. doi: 10.1371/journal.pone.0028994

Asea, A. A., and Brown, I. R. (2008). Heat Shock Proteins in the Brain: Implications for Neurodegenerative Diseases and Neuroprotection. New York: Springer, $1-285$.

Atwood, H. L., and Karunanithi, S. (2002). Diversification of synaptic strength: presynaptic elements. Nat. Rev. Neurosci. 3, 497-516. doi: 10.1038/ nrn876

Barclay, J. W., Atwood, H. L., and Robertson, R. M. (2002). Impairment of central pattern generation in Drosophila cysteine string protein mutants. J. Comp. Physiol. A Neuroethol. Sens. Neural Behav. Physiol. 188, 71-78. doi: 10. 1007/s00359-002-0279-9

Barclay, J. W., and Robertson, R. M. (2000). Heat-shock-induced thermoprotection of hindleg motor control in the locust. J. Exp. Biol. 203, 941-950

Barclay, J. W., and Robertson, R. M. (2003). Role for calcium in heat shockmediated synaptic thermoprotection in Drosophila larvae. J. Neurobiol. 56, 360-371. doi: 10.1002/neu.10247

Bechtold, D. A., and Brown, I. R. (2000). Heat shock proteins Hsp27 and Hsp32 localize to synaptic sites in the rat cerebellum following hyperthermia. Brain Res. Mol. Brain Res. 75, 309-320. doi: 10.1016/s0169-328x(99) 00323-x

\section{Concluding Remarks}

Heat shock response is a mechanism that preserves cellular functions under stress through the upregulation of HSPs. Homeostatic plasticity is a mechanism that preserves the activities of neurons and their target cells around their respective set points in the face of stress. Therefore we propose that the heat shock response may afford homeostatic plasticity. In this review, we have sought to provide examples from literature suggesting that the heat shock response affords homeostatic plasticity. Currently, investigations of the link between the two mechanisms are scant. By providing such examples, we hope to stimulate the interest of readers to further explore the interface between these two mechanisms.

Certain disorders, such as seizures, sleep disturbances and cognitive disorders are thought to result, in part, from disruptions of homeostatic plasticity (Burke and Barnes, 2010; Wang et al., 2011; Huguet et al., 2013; Swann and Rho, 2014; Tononi and Cirelli, 2014). HSPs have been shown to ameliorate the symptoms of these disorders (Shaw et al., 2002; Naidoo et al., 2008; Su et al., 2009; Ekimova et al., 2010; Vizcaychipi et al., 2011; Hashimoto-Torii et al., 2014). Whether the ameliorative effects of the heat shock response are produced through the recruitment of homeostatic plasticity will be a fascinating field of study that may have clinical implications.

\section{Acknowledgments}

SK was supported by grants from Griffith University and the ARC, and IRB was supported by grants from NSERC. We like to thank Annette Vella for proofreading the manuscript.

Bechtold, D. A., and Brown, I. R. (2003). Induction of Hsp27 and Hsp32 stress proteins and vimentin in glial cells of the rat hippocampus following hyperthermia. Neurochem. Res. 28, 1163-1173. doi: 10.1023/A:10242681 26310

Bechtold, D. A., Rush, S. J., and Brown, I. R. (2000). Localization of the heatshock protein Hsp70 to the synapse following hyperthermic stress in the brain. J. Neurochem. 74, 641-646. doi: 10.1046/j.1471-4159.2000.740641.x

Bishop, H. I., and Zito, K. (2013). The downs and ups of sensory deprivation: evidence for firing rate homeostasis in vivo. Neuron 80, 247-249. doi: 10.1016/j. neuron.2013.10.011

Bronk, P., Nie, Z., Klose, M. K., Dawson-Scully, K., Zhang, J., Robertson, R. M., et al. (2005). The multiple functions of cysteine-string protein analyzed at Drosophila nerve terminals. J. Neurosci. 25, 2204-2214. doi: 10.1523/jneurosci. 3610-04.2005

Bronk, P., Wenniger, J. J., Dawson-Scully, K., Guo, X., Hong, S., Atwood, H. L., et al. (2001). Drosophila Hsc70-4 is critical for neurotransmitter exocytosis in vivo. Neuron 30, 475-488. doi: 10.1016/s0896-6273(01)00292-6

Brown, I. R. (2007). Heat shock proteins and protection of the nervous system. Ann. N Y Acad. Sci. 1113, 147-158. doi: 10.1196/annals.1391.032

Buccellato, M. A., Carsillo, T., Traylor, Z., and Oglesbee, M. (2007). Heat shock protein expression in brain: a protective role spanning intrinsic thermal resistance and defense against neurotropic viruses. Prog. Brain Res. 162, 395-415. doi: 10.1016/s0079-6123(06)62019-0

Burke, S. N., and Barnes, C. A. (2010). Senescent synapses and hippocampal circuit dynamics. Trends Neurosci. 33, 153-161. doi: 10.1016/j.tins.2009. 12.003 
Burré, J., Sharma, M., Tsetsenis, T., Buchman, V., Etherton, M. R., and Südhof, T. C. (2010). Alpha-synuclein promotes SNARE-complex assembly in vivo and in vitro. Science 329, 1663-1667. doi: 10.1126/science.1195227

Burrone, J., and Murthy, V. N. (2003). Synaptic gain control and homeostasis. Curr. Opin. Neurobiol. 13, 560-567. doi: 10.1016/j.conb.2003.09.007

Casson, R. J., Chidlow, G., Ebneter, A., Wood, J. P., Crowston, J., and Goldberg, I. (2012). Translational neuroprotection research in glaucoma: a review of definitions and principles. Clin. Experiment. Ophthalmol. 40, 350-357. doi: 10. 1111/j.1442-9071.2011.02563.x

Chen, S., and Brown, I. R. (2007). Translocation of constitutively expressed heat shock protein Hsc70 to synapse-enriched areas of the cerebral cortex after hyperthermic stress. J. Neurosci. Res. 85, 402-409. doi: 10.1002/jnr. 21124

Clay, J. R., and Kuzirian, A. (2002). Trafficking of axonal $\mathrm{K}^{+}$channels: potential role of Hsc70. J. Neurosci. Res. 67, 745-752. doi: 10.1002/jnr.10182

Davis, G. W. (2006). Homeostatic control of neural activity: from phenomenology to molecular design. Annu. Rev. Neurosci. 29, 307-323. doi: 10.1146/annurev. neuro.28.061604.135751

Davis, G. W. (2013). Homeostatic signaling and the stabilization of neural function. Neuron 80, 718-728. doi: 10.1016/j.neuron.2013.09.044

Davis, G. W., and Müller, M. (2015). Homeostatic control of presynaptic neurotransmitter release. Annu. Rev. Physiol. 77, 251-270. doi: 10. 1146/annurev-physiol-021014-071740

Dawson-Scully, K., and Meldrum Robertson, R. (1998). Heat shock protects synaptic transmission in flight motor circuitry of locusts. Neuroreport 9, 2589-2593. doi: 10.1097/00001756-199808030-00030

Debanne, D., Campanac, E., Bialowas, A., Carlier, E., and Alcaraz, G. (2011). Axon physiology. Physiol. Rev. 91, 555-602. doi: 10.1152/physrev.00048.2009

De Maio, A. (1999). Heat shock proteins: facts, thoughts and dreams. Shock 11, 1-12. doi: 10.1097/00024382-199901000-00001

De Maio, A., and Vazquez, D. (2013). Extracellular heat shock proteins: a new location, a new function. Shock 40, 239-246. doi: 10.1097/shk. $0 \mathrm{~b} 013 \mathrm{e} 3182 \mathrm{a} 185 \mathrm{ab}$

Desai, N. S. (2003). Homeostatic plasticity in the CNS: synaptic and intrinsic forms. J. Physiol. Paris 97, 391-402. doi: 10.1016/j.jphysparis.2004. 01.005

Ekimova, I. V., Nitsinskaya, L. E., Romanova, I. V., Pastukhov, Y. F., Margulis, B. A., and Guzhova, I. V. (2010). Exogenous protein Hsp70/Hsc70 can penetrate into brain structures and attenuate the severity of chemically-induced seizures. J. Neurochem. 115, 1035-1044. doi: 10.1111/j.1471-4159.2010. 06989.x

Feder, M. E., Cartano, N. V., Milos, L., Krebs, R. A., and Lindquist, S. L. (1996). Effect of engineering Hsp70 copy number on Hsp70 expression and tolerance of ecologically relevant heat shock in larvae and pupae of Drosophila melanogaster. J. Exp. Biol. 199, 1837-1844.

Feder, M. E., Garland, T. Jr., Marden, J. H., and Zera, A. J. (2010). Locomotion in response to shifting climate zones: not so fast. Annu. Rev. Physiol. 72, 167-190. doi: 10.1146/annurev-physiol-021909-135804

Fei, G., Guo, C., Sun, H. S., and Feng, Z. P. (2007). Chronic hypoxia stress-induced differential modulation of heat-shock protein 70 and presynaptic proteins. J. Neurochem. 100, 50-61. doi: 10.1111/j.1471-4159.2006.04194.x

Fei, G., Guo, C., Sun, H. S., and Feng, Z. P. (2008). HSP70 reduces chronic hypoxiainduced neural suppression via regulating expression of syntaxin. Adv. Exp. Med. Biol. 605, 35-40. doi: 10.1007/978-0-387-73693-8_6

Ficker, E., Dennis, A. T., Wang, L., and Brown, A. M. (2003). Role of the cytosolic chaperones Hsp70 and Hsp90 in maturation of the cardiac potassium channel HERG. Circ. Res. 92, e87-e100. doi: 10.1161/01.res.0000079028. 31393.15

Freedman, M. S., Clark, B. D., Cruz, T. F., Gurd, J. W., and Brown, I. R. (1981). Selective effects of LSD and hyperthermia on the synthesis of synaptic proteins and glycoproteins. Brain Res. 207, 129-145. doi: 10.1016/0006-8993(81) 90683-1

Gao, Y., Yechikov, S., Vazquez, A. E., Chen, D., and Nie, L. (2013a). Distinct roles of molecular chaperones HSP90alpha and HSP90beta in the biogenesis of KCNQ4 channels. PLoS One 8:e57282. doi: 10.1371/journal.pone.0057282

Gao, Y., Yechikov, S., Vazquez, A. E., Chen, D., and Nie, L. (2013b). Impaired surface expression and conductance of the KCNQ4 channel lead to sensorineural hearing loss. J. Cell. Mol. Med. 17, 889-900. doi: 10.1111/jcmm. 12080
Gidalevitz, T., Prahlad, V., and Morimoto, R. I. (2011). The stress of protein misfolding: from single cells to multicellular organisms. Cold Spring Harb. Perspect. Biol. 3:a009704. doi: 10.1101/cshperspect.a009704

Hartl, F. U., and Hayer-Hartl, M. (2009). Converging concepts of protein folding in vitro and in vivo. Nat. Struct. Mol. Biol. 16, 574-581. doi: 10.1038/nsmb. 1591

Hashimoto-Torii, K., Torii, M., Fujimoto, M., Nakai, A., El Fatimy, R., Mezger, V., et al. (2014). Roles of heat shock factor 1 in neuronal response to fetal environmental risks and its relevance to brain disorders. Neuron 82, 560-572. doi: 10.1016/j.neuron.2014.03.002

Hengen, K. B., Lambo, M. E., Van Hooser, S. D., Katz, D. B., and Turrigiano, G. G. (2013). Firing rate homeostasis in visual cortex of freely behaving rodents. Neuron 80, 335-342. doi: 10.1016/j.neuron.2013.08.038

Hou, N., Armstrong, G. A., Chakraborty-Chatterjee, M., Sokolowski, M. B., and Robertson, R. M. (2014). $\mathrm{Na}^{+}-\mathrm{K}^{+}$-ATPase trafficking induced by heat shock pretreatment correlates with increased resistance to anoxia in locusts. J. Neurophysiol. 112, 814-823. doi: 10.1152/jn.00201.2014

Huguet, G., Ey, E., and Bourgeron, T. (2013). The genetic landscapes of autism spectrum disorders. Annu. Rev. Genomics Hum. Genet. 14, 191-213. doi: 10. 1146/annurev-genom-091212-153431

Kampinga, H. H., Hageman, J., Vos, M. J., Kubota, H., Tanguay, R. M., Bruford, E. A., et al. (2009). Guidelines for the nomenclature of the human heat shock proteins. Cell Stress Chaperones 14, 105-111. doi: 10.1007/s12192-008-0068-7

Karunanithi, S., Barclay, J. W., Brown, I. R., Robertson, R. M., and Atwood, H. L. (2002). Enhancement of presynaptic performance in transgenic Drosophila overexpressing heat shock protein Hsp70. Synapse 44, 8-14. doi: 10.1002/syn. 10048

Karunanithi, S., Barclay, J. W., Robertson, R. M., Brown, I. R., and Atwood, H. L. (1999). Neuroprotection at Drosophila synapses conferred by prior heat shock. J. Neurosci. 19, 4360-4369.

Keck, T., Keller, G. B., Jacobsen, R. I., Eysel, U. T., Bonhoeffer, T., and Hübener, M. (2013). Synaptic scaling and homeostatic plasticity in the mouse visual cortex in vivo. Neuron 80, 327-334. doi: 10.1016/j.neuron.2013.08.018

Kelty, J. D., Noseworthy, P. A., Feder, M. E., Robertson, R. M., and Ramirez, J. M. (2002). Thermal preconditioning and heat-shock protein 72 preserve synaptic transmission during thermal stress. J. Neurosci. 22:RC193.

Klose, M. K., Armstrong, G., and Robertson, R. M. (2004). A role for the cytoskeleton in heat-shock-mediated thermoprotection of locust neuromuscular junctions. J. Neurobiol. 60, 453-462. doi: 10.1002/neu.20058

Klose, M. K., Atwood, H. L., and Robertson, R. M. (2008). Hyperthermic preconditioning of presynaptic calcium regulation in Drosophila. J. Neurophysiol. 99, 2420-2430. doi: 10.1152/jn.01251.2007

Klose, M. K., Boulianne, G. L., Robertson, R. M., and Atwood, H. L. (2009). Role of ATP-dependent calcium regulation in modulation of Drosophila synaptic thermotolerance. J. Neurophysiol. 102, 901-913. doi: 10.1152/jn.91209. 2008

Klose, M. K., Chu, D., Xiao, C., Seroude, L., and Robertson, R. M. (2005). Heat shock-mediated thermoprotection of larval locomotion compromised by ubiquitous overexpression of $\mathrm{Hsp} 70$ in Drosophila melanogaster. J. Neurophysiol. 94, 3563-3572. doi: 10.1152/jn.00723.2005

Kourtis, N., Nikoletopoulou, V., and Tavernarakis, N. (2012). Small heat-shock proteins protect from heat-stroke-associated neurodegeneration. Nature 490 , 213-218. doi: 10.1038/nature11417

Krieger, A., Radhakrishnan, K., Pereverzev, A., Siapich, S. A., Banat, M., Kamp, M. A., et al. (2006). The molecular chaperone hsp70 interacts with the cytosolic II-III loop of the $\mathrm{Ca}_{v} 2.3$ E-type voltage-gated Ca2+ channel. Cell. Physiol. Biochem. 17, 97-110. doi: 10.1159/000092071

Latchman, D. S. (2004). Protective effect of heat shock proteins in the nervous system. Curr. Neurovasc. Res. 1, 21-27. doi: 10.2174/1567202043480206

Macleod, G. T., Chen, L., Karunanithi, S., Peloquin, J. B., Atwood, H. L., McRory, J. E., et al. (2006). The Drosophila cacts 2 mutation reduces presynaptic $\mathrm{Ca}^{2+}$ entry and defines an important element in $\mathrm{Ca}_{v} 2.1$ channel inactivation. Eur. J. Neurosci. 23, 3230-3244. doi: 10.1111/j.1460-9568.2006.04873.x

Marder, E., and Goaillard, J. M. (2006). Variability, compensation and homeostasis in neuron and network function. Nat. Rev. Neurosci. 7, 563-574. doi: 10. 1038/nrn1949

Marder, E., and Prinz, A. A. (2002). Modeling stability in neuron and network function: the role of activity in homeostasis. Bioessays 24, 1145-1154. doi: 10 . 1002/bies. 10185 
Misonou, H. (2010). Homeostatic regulation of neuronal excitability by $\mathrm{K}(+)$ channels in normal and diseased brains. Neuroscientist 16, 51-64. doi: 10 . $1177 / 1073858409341085$

Money, T. G., Anstey, M. L., and Robertson, R. M. (2005). Heat stress-mediated plasticity in a locust looming-sensitive visual interneuron. J. Neurophysiol. 93, 1908-1919. doi: 10.1152/jn.00908.2004

Money, T. G., Rodgers, C. I., McGregor, S. M., and Robertson, R. M. (2009). Loss of potassium homeostasis underlies hyperthermic conduction failure in control and preconditioned locusts. J. Neurophysiol. 102, 285-293. doi: 10.1152/jn. 91174.2008

Morimoto, R. I. (2011). The heat shock response: systems biology of proteotoxic stress in aging and disease. Cold Spring Harb. Symp. Quant. Biol. 76, 91-99. doi: 10.1101/sqb.2012.76.010637

Naidoo, N., Ferber, M., Master, M., Zhu, Y., and Pack, A. I. (2008). Aging impairs the unfolded protein response to sleep deprivation and leads to proapoptotic signaling. J. Neurosci. 28, 6539-6548. doi: 10.1523/jneurosci.5685-07. 2008

Neal, S. J., Karunanithi, S., Best, A., So, A. K., Tanguay, R. M., Atwood, H. L., et al. (2006). Thermoprotection of synaptic transmission in a Drosophila heat shock factor mutant is accompanied by increased expression of Hsp83 and DnaJ-1. Physiol. Genomics 25, 493-501. doi: 10.1152/physiolgenomics.00195.2005

Newman, A. E., Xiao, C., and Robertson, R. M. (2005). Synaptic thermoprotection in a desert-dwelling Drosophila species. J. Neurobiol. 64, 170-180. doi: 10. 1002/neu.20132

Parsell, D. A., and Lindquist, S. (1993). The function of heat-shock proteins in stress tolerance: degradation and reactivation of damaged proteins. Annu. Rev. Genet. 27, 437-496. doi: 10.1146/annurev.genet.27.1.437

Pozo, K., and Goda, Y. (2010). Unraveling mechanisms of homeostatic synaptic plasticity. Neuron 66, 337-351. doi: 10.1016/j.neuron.2010.04.028

Pulver, S. R., and Griffith, L. C. (2010). Spike integration and cellular memory in a rhythmic network from $\mathrm{Na}^{+} / \mathrm{K}^{+}$pump current dynamics. Nat. Neurosci. 13, 53-59. doi: 10.1038/nn.2444

Ramirez, J. M., Elsen, F. P., and Robertson, R. M. (1999). Long-term effects of prior heat shock on neuronal potassium currents recorded in a novel insect ganglion slice preparation. J. Neurophysiol. 81, 795-802.

Riordan, M., Sreedharan, R., Wang, S., Thulin, G., Mann, A., Stankewich, M., et al. (2005). HSP70 binding modulates detachment of Na-K-ATPase following energy deprivation in renal epithelial cells. Am. J. Physiol. Renal Physiol. 288, F1236-F1242. doi: 10.1152/ajprenal.00438.2004

Rizo, J., and Südhof, T. C. (2012). The membrane fusion enigma: SNAREs, Sec1/Munc18 proteins and their accomplices-guilty as charged? Annu. Rev. Cell Dev. Biol. 28, 279-308. doi: 10.1146/annurev-cellbio-101011-155818

Robertson, R. M., and Money, T. G. (2012). Temperature and neuronal circuit function: compensation, tuning and tolerance. Curr. Opin. Neurobiol. 22, 724-734. doi: 10.1016/j.conb.2012.01.008

Robertson, R. M., Xu, H., Shoemaker, K. L., and Dawson-Scully, K. (1996). Exposure to heat shock affects thermosensitivity of the locust flight system. J. Neurobiol. 29, 367-383. doi: 10.1002/(sici)1097-4695(199603)29:3<367::aidneu8 $>3.0 . \mathrm{co} ; 2-7$

Ruete, M. C., Carrizo, L. C., and Vallés, P. G. (2008). Na ${ }^{+} / \mathrm{K}^{+}$-ATPase stabilization by Hsp70 in the outer stripe of the outer medulla in rats during recovery from a low-protein diet. Cell Stress Chaperones 13, 157-167. doi: 10.1007/s12192-0080021-9

Saibil, H. (2013). Chaperone machines for protein folding, unfolding and disaggregation. Nat. Rev. Mol. Cell Biol. 14, 630-642. doi: 10.1038/nrm3658

Sharma, M., Burré, J., and Südhof, T. C. (2011). CSPalpha promotes SNAREcomplex assembly by chaperoning SNAP-25 during synaptic activity. Nat. Cell Biol. 13, 30-39. doi: 10.1038/ncb2131

Shaw, P. J., Tononi, G., Greenspan, R. J., and Robinson, D. F. (2002). Stress response genes protect against lethal effects of sleep deprivation in Drosophila. Nature 417, 287-291. doi: 10.1038/417287a

Stetler, R. A., Gan, Y., Zhang, W., Liou, A. K., Gao, Y., Cao, G., et al. (2010). Heat shock proteins: cellular and molecular mechanisms in the central nervous system. Prog. Neurobiol. 92, 184-211. doi: 10.1016/j.pneurobio.2010.05.002
Stewart, B. A., Schuster, C. M., Goodman, C. S., and Atwood, H. L. (1996). Homeostasis of synaptic transmission in Drosophila with genetically altered nerve terminal morphology. J. Neurosci. 16, 3877-3886.

Su, Z., Han, D., Sun, B., Qiu, J., Li, Y., Li, M., et al. (2009). Heat stress preconditioning improves cognitive outcome after diffuse axonal injury in rats. J. Neurotrauma 26, 1695-1706. doi: 10.1089/neu.2008.0519

Swann, J. W., and Rho, J. M. (2014). How is homeostatic plasticity important in epilepsy? Adv. Exp. Med. Biol. 813, 123-131. doi: 10.1007/978-94-017-89141_10

Tissières, A., Mitchell, H. K., and Tracy, U. M. (1974). Protein synthesis in salivary glands of Drosophila melanogaster: relation to chromosome puffs. J. Mol. Biol. 84, 389-398. doi: 10.1016/0022-2836(74)90447-1

Tononi, G., and Cirelli, C. (2014). Sleep and the price of plasticity: from synaptic and cellular homeostasis to memory consolidation and integration. Neuron 81 , 12-34. doi: 10.1016/j.neuron.2013.12.025

Turrigiano, G. G. (1999). Homeostatic plasticity in neuronal networks: the more things change, the more they stay the same. Trends Neurosci. 22, 221-227. doi: 10.1016/s0166-2236(98)01341-1

Turrigiano, G. G. (2008). The self-tuning neuron: synaptic scaling of excitatory synapses. Cell 135, 422-435. doi: 10.1016/j.cell.2008.10.008

Turrigiano, G. (2011). Too many cooks? Intrinsic and synaptic homeostatic mechanisms in cortical circuit refinement. Annu. Rev. Neurosci. 34, 89-103. doi: 10.1146/annurev-neuro-060909-153238

Turrigiano, G. (2012). Homeostatic synaptic plasticity: local and global mechanisms for stabilizing neuronal function. Cold Spring Harb. Perspect. Biol. 4:a005736. doi: 10.1101/cshperspect.a005736

Turrigiano, G. G., and Nelson, S. B. (2004). Homeostatic plasticity in the developing nervous system. Nat. Rev. Neurosci. 5, 97-107. doi: 10. $1038 /$ nrn1327

Tytell, M., Greenberg, S. G., and Lasek, R. J. (1986). Heat shock-like protein is transferred from glia to axon. Brain Res. 363, 161-164. doi: 10.1016/00068993(86)90671-2

van Oosten-Hawle, P., and Morimoto, R. I. (2014). Transcellular chaperone signaling: an organismal strategy for integrated cell stress responses. J. Exp. Biol. 217, 129-136. doi: 10.1242/jeb.091249

Vizcaychipi, M. P., Xu, L., Barreto, G. E., Ma, D., Maze, M., and Giffard, R. G. (2011). Heat shock protein 72 overexpression prevents early postoperative memory decline after orthopedic surgery under general anesthesia in mice. Anesthesiology 114, 891-900. doi: 10.1097/aln.0b013e31820ad3ce

Wang, G., Grone, B., Colas, D., Appelbaum, L., and Mourrain, P. (2011). Synaptic plasticity in sleep: learning, homeostasis and disease. Trends Neurosci. 34, 452-463. doi: 10.1016/j.tins.2011.07.005

Wang, T., Hauswirth, A. G., Tong, A., Dickman, D. K., and Davis, G. W. (2014). Endostatin is a trans-synaptic signal for homeostatic synaptic plasticity. Neuron 83, 616-629. doi: 10.1016/j.neuron.2014.07.003

Wray, D. (2009). Intracellular regions of potassium channels: $\mathrm{K}_{v} 2.1$ and heag. Eur. Biophys. J. 38, 285-292. doi: 10.1007/s00249-008-0354-4

Wu, B. S., Walker, V. K., and Robertson, R. M. (2001). Heat shock-induced thermoprotection of action potentials in the locust flight system. J. Neurobiol. 49, 188-199. doi: 10.1002/neu.1074

Xiao, C., Mileva-Seitz, V., Seroude, L., and Robertson, R. M. (2007). Targeting HSP70 to motoneurons protects locomotor activity from hyperthermia in Drosophila. Dev. Neurobiol. 67, 438-455. doi: 10.1002/dneu.20344

Conflict of Interest Statement: The authors declare that the research was conducted in the absence of any commercial or financial relationships that could be construed as a potential conflict of interest.

Copyright (C) 2015 Karunanithi and Brown. This is an open-access article distributed under the terms of the Creative Commons Attribution License (CC BY). The use, distribution and reproduction in other forums is permitted, provided the original author(s) or licensor are credited and that the original publication in this journal is cited, in accordance with accepted academic practice. No use, distribution or reproduction is permitted which does not comply with these terms. 